\title{
Planejamento do Turismo a partir da Perspectiva Actor-Centered Power no Parque Estadual da Ilha Grande, Rio de Janeiro, Brasil
}

\author{
Carolina Dutra de Araujoa \\ Débora Regina Campos Cândido ${ }^{b}$ \\ Max Krott ${ }^{\mathrm{c}}$
}

\begin{abstract}
Resumo
Usualmente, o planejamento do turismo no Brasil segue a perspectiva normativa em sua execução. Este estudo propõe integrar a perspectiva actor-centered power ao planejamento a fim de elucidar quais são os atores sociais mais poderosos e quais são seus interesses no desenvolvimento turístico. Tal perspectiva é possível por meio da identificação desses atores e de sua relação com a coerção, a informação dominante e incentivos e desincentivos, categorias derivadas das abordagens de poder desenvolvidas por Krott. Para cumprir o objetivo proposto, realizou-se entrevistas mediante a técnica bola de neve. A hipótese de pesquisa é que o planejamento do turismo no Parque Estadual da Ilha Grande (Rio de Janeiro, Brasil) é direcionado pelos interesses dos atores sociais mais poderosos. Os resultados confirmam tal hipótese e demostram que há grande conflito de interesses entre ONGs, governo e administração da Unidade de Conservação. Palavras-chave: Planejamento do turismo; Actor-centered power; Parque Estadual da Ilha Grande; Brasil.
\end{abstract}

\begin{abstract}
Tourism planning based on the actor-centered power perspective in the Ilha Grande State Park, Rio de Janeiro, Brazil

Usually, tourism planning in Brazil follows the normative perspective in its implementation. This study proposes to integrate the actor-centered power perspective with planning in order to elucidate which are the most powerful social actors and what are their interests in tourism development. Such perspective is enabled through the identification of these actors and their relation with coercion, dominant information, and incentives and disincentives, categories derived from the approaches to power developed by Krott. In order to achieve the objective, interviews were conducted by employing the snowball technique. The research hypothesis is that tourism planning in the Ilha Grande State Park (Rio de Janeiro, Brazil) is directed by the interests of the most powerful social actors. The results confirm such hypothesis and show that there is great conflict of interests between NGOs, Government, and the administration of the Conservation Unit.
\end{abstract}

Keywords: Tourism planning; ; Ilha Grande State Park; Brazil.

a. Doutoranda em Ciências Florestais e Ecologia Florestal pela Georg-August-Universität Göttingen, Göttingen, Alemanha. E-mail: dutracarolina@gmail.com

b. Professora substituta da Universidade Federal Rural do Rio de Janeiro, Nova Iguaçu, Rio de Janeiro, Brasil. E-mail: debora.rcc@hotmail.com

c. Chefe do departamento de Forest and Nature Conservation Policy da Faculdade de Forest Sciences and Forest Ecology da Georg-August-Universität-Göttingen, Göttingen, Alemanha. E-mail: mkrott@gwdg.de 


\section{Resumen}

La planificación del turismo a partir de la perspectiva actor-centered power en el Parque Estatal de Isla Grande, Rio de Janeiro, Brasil

Por lo general, el planeamiento del turismo en Brasil sigue la perspectiva normativa en su aplicación. Este estudio propone la integración de la perspectiva actor-centered power (Krott et al., 2014) a la planificación para dilucidar cuales son los actores sociales más poderosos y cuáles son sus intereses en el desarrollo del turismo. Tal perspectiva es posible a través de la identificación de estos actores y de su relación con la coacción, la información dominante y los incentivos y desincentivos, categorías derivadas de los enfoques del poder desarrollados por Krott (2005). Para cumplir con el objetivo propuesto, se llevó a cabo entrevistas realizadas por medio de la técnica bola de nieve. La hipótesis de la investigación es que la ordenación del turismo en el Parque Estatal de Ilha Grande (Río de Janeiro, Brasil) es dirigida por los intereses de los actores sociales más poderosos. Los resultados confirman esta hipótesis y demuestran que hay un gran conflicto de intereses entre las ONGs, gobierno y administración de la Unidad de Conservación.

Palabras clave: Planificación del turismo; Actor-centered power; Parque Estatal de Ilha Grande; Brasil.

\section{INTRODUÇÃO}

O planejamento do turismo no Brasil costuma levar em conta a perspectiva normativa baseada em objetivos a serem alcançados por meio de passos bem definidos para sua execução (BENI, 2006; BEZERRA, 2003; BRAGA, 2006; PANOSSO NETO; ANSARAH, 2008; PETROCCHI, 1998; RUSCHMANN; SOLHA, 2005;). Politicamente, os entraves para esse desenvolvimento são grandes, devido aos interesses conflitantes dos diversos atores envolvidos no processo. Portanto, a análise actor-centered power (KROTT et. al., 2014) emerge como uma ferramenta para identificação de atores poderosos e seus interesses no desenvolvimento turístico de determinado local.

O objetivo deste estudo é analisar criticamente a perspectiva normativa do planejamento do turismo à luz da abordagem de poder que leva em conta fatores como coerção, informação dominante e incentivos.

Acredita-se que a análise actor-centered power possa ser incluída em processos de planejamento e elaboração de políticas públicas, servindo como ferramenta capaz de identificar os entraves ao desenvolvimento turístico de determinado local. Normalmente utilizada em estudos realizados em florestas comunitárias, a análise actor-centered power busca identificar os entraves para o sucesso de um determinado projeto através da determinação de atores, interesses e elementos de poder (KROTT et al., 2014; MARYUDI et al., 2012; SCHUSSER, 2013; SCHUSSER et al., 2015; SCHUSSER et al., 2016).

Conforme Krott et al. (2014, p. 34), a abordagem actor-centered power tem por objetivo fornecer uma reposta científica que permita identificar os atores políticos mais poderosos numa comunidade florestal. Nesse sentido, pode-se definir actor-centered power como uma relação social na qual o ator A altera o comportamento do ator B sem reconhecer a vontade deste último. É, portanto, uma abordagem de análise dos interesses dos atores em relação a uma determinada perspectiva política. 
A fim de alcançar o objetivo deste trabalho, foram entrevistados, em novembro de 2014, nove atores sociais com poder de influência sobre o desenvolvimento do turismo no Parque Estadual da Ilha Grande (Rio de Janeiro). Os entrevistados foram definidos por meio do processo "bola de neve" (o entrevistado indica outra pessoa a ser interrogada), e, finalmente, após as entrevistas, os dados foram sistematizados e analisados segundo a abordagem actor-centered power.

\section{PERSPECTIVA NORMATIVA DO PLANEJAMENTO TURÍSTICO NO BRASIL}

O planejamento turístico no Brasil advém de uma recente experiência de políticas públicas indissociáveis do processo de criação de um ministério específico para a atividade. Até o início dos anos 2000, embora o país já houvesse experimentado diversas iniciativas na área do turismo, ainda não havia um ministério exclusivo para o setor. A partir da criação da pasta, uma maior organização dos esforços para a concepção e implementação de políticas públicas se estabelece, e, hoje, mais de quinze anos depois, já é possível discutir alguns resultados dessas iniciativas.

As políticas públicas de turismo no Brasil estruturam-se com base em uma perspectiva economicista e normativa. Economicista, uma vez que as iniciativas de organização da atividade estruturaram-se com base em seus benefícios econômicos. E normativa, na medida em que a organização da atividade turística é influenciada por sistemas de organização dos setores que a compõem. Exceções à regra baseadas na participação social, como o turismo de base comunitária, por exemplo, raramente são implementadas com sucesso.

De acordo com Solha (2002, p. 118), a evolução do turismo no Brasil, e, com isso, das políticas públicas para sua regulação, pode ser representada por cinco períodos diferentes:

1. Colônia e império (séculos VXII e XIX): primórdios da atividade com os primeiros fluxos de viajantes e a hospitalidade aos tropeiros, além de viagens dos senhores de engenho à Europa;

2. de 1900 a 1949: estações de cura e cassinismo, expansão das rodovias e intensificação das viagens por esse modal;

3. de 1950 a 1969: expansão e organização do turismo com ampliação da infraestrutura de transportes, organização da atividade por meio de associações e da estruturação de políticas;

4. de 1970 a 1989: estagnação do ritmo de crescimento verificado no período anterior e subsequente decrescimento;

5. de 1990 a 2000: crescimento do mercado interno, investimentos de maior vulto em diferentes setores e exploração de novos segmentos de mercado.

Já Beni (2006, p. 25-33) traz uma retrospectiva do desenvolvimento do turismo a partir da revisão de programas de financiamento e desenvolvimento, em uma análise que se inicia na década de 1970 e chega ao início dos anos 2000. Segundo o autor, as políticas públicas de turismo tradicionalmente refletiam, à época, uma visão orientada para a iniciativa privada, não levando-se em consideração a participação da sociedade civil. 
Anteriores a esse período, destacam-se algumas intervenções governamentais que interferiram direta ou indiretamente no turismo, tais como a proteção de bens históricos e artísticos e a fiscalização de agências de venda de passagens (1937-1945); a criação do Ministério da Justiça e Negócios (1946-1962); a criação do Ministério do Trabalho, Indústria e Comércio e o início do planejamento do turismo em nível nacional com a Companhia Brasileira de Turismo (Combratur) (1948-1958), posteriormente subordinada diretamente à Presidência da República (1959-1966); a criação da divisão de Turismo e Certames do Departamento Nacional do Comércio e as criações posteriores da Empresa Brasileira de Turismo (Embratur) e do Conselho Nacional de Turismo (CNTur), com a definição de uma Política Nacional de Turismo (1963-1966) (BENI, 2006, p. 19-20).

É importante observar que a gestão pública do turismo influencia as mudanças na gestão do patrimônio cultural e do meio ambiente, e que as leis que amparam estas duas áreas refletem importantes mudanças na atividade turística.

A partir da década de 1970, visando atrair empresários do setor de turismo, foram instituídos fundos de financiamento para projetos de desenvolvimento da atividade turística gerenciados pela Embratur. Entretanto, segundo Beni (2006, p. 24), o capital oriundo desses incentivos foram empregados quase que integralmente em hotéis de luxo, criando uma oferta incompatível com as demandas internas e os fluxos externos daquele momento. Entre as iniciativas importantes dessa década, estão a criação de leis visando a organização e fiscalização de serviços turísticos e a valorização de zonas e locais de interesse turístico.

Posteriormente, nos anos 1980, inicia-se a transição do regime militar para a democracia, com um processo de abertura política que culminou na criação de uma nova Constituição, onde o turismo é citado no Art. 180. 0 espaço para debate então se amplia, e a nova organização política interfere no turismo. Do ponto de vista institucional, acreditou-se que a melhor configuração para o desenvolvimento do setor seria a organização de um colegiado formado pela Embratur, CNTur e Ministério da Indústria e Comércio. Ocorrem ações de estímulo ao turismo interno e liberação de mercado para o exercício de atividades turísticas (BENI, 2006, p. 25-26). Entre as iniciativas do período, vale destacar também o estabelecimento da Política Nacional do Meio Ambiente, que influencia a formulação de políticas públicas e a organização do turismo.

Nota-se nos períodos pré e pós-redemocratização que, apesar da presença do setor público, as iniciativas de planejamento do turismo se centravam na atividade econômica em detrimento de aspectos sociais. Considerando a totalidade complexa que constitui o turismo, pode-se considerar esse tipo de iniciativas como reducionista, incapaz de organizar e direcionar esforços de todos os setores da sociedade envolvidos.

Na década de 1990, percebe-se maior atividade nos órgãos turísticos oficiais, o que, por outro lado, permite constatar o quanto o turismo não esteve entre as prioridades de governo até então. Neste período, foi criado o Ministério da Indústria, Comércio e Turismo, ocorreu a revitalização do Fundo Geral de Turismo (Fungetur), a apresentação do Plano Nacional de Turismo (Plantur), do Programa de Desenvolvimento do Turismo (Prodetur) e do Programa de Desenvolvimento do Ecoturismo na Amazônia Legal (Proecotur). Tais programas demonstram o foco no desenvolvimento do turismo na natureza e no incentivo ao turismo de sol e praia, vocações que acabaram se consolidando. Neste período, também foi formulado o 
programa Parques do Brasil, que, numa parceria entre o IBAMA e a Embratur, propôs ações visando a geração de efeitos sociais benéficos para moradores locais, com destaque para o Parque Nacional do Iguaçu (BENI, 2006, p. 25-26).

Uma ação significativa desse período é a criação do Programa Nacional de Municipalização do Turismo (PNMT), que marca o início do estabelecimento de diretrizes para a organização e desenvolvimento do turismo. A ideia do PNMT era promover o desenvolvimento dos municípios por meio da sensibilização aos benefícios da atividade turística. Assim, visando disseminar esses ideais, organizou-se uma grande estrutura de formação de multiplicadores a partir de oficinas. Pretendia-se, com base em recomendações da Organização Mundial de Turismo (OMT), se empreender um processo de interiorização da atividade turística. 0 fato, entretanto, é que o modelo pressupunha um conhecimento do espaço e das vocações turísticas do país, suas regiões e localidades; e, nas oficinas, muitos municípios declararam-se vocacionados para o turismo mesmo antes de inventariar sua estrutura e atrativos. Ainda como obstáculo para o sucesso da iniciativa, há que se considerar a grande dimensão territorial e a dificuldade de conciliar tantas particularidades, ou mesmo de se acompanhar o resultado da ação dos multiplicadores. Uma particularidade do PNMT é que as oficinas de municipalização do turismo reuniam grupos de várias localidades do país, o que de certa forma favorecia uma perspectiva de base local, na medida em que os participantes estabeleciam metas de desenvolvimento para seus destinos e assumiam compromissos com a multiplicação das ideias. Por outro lado, percebe-se no programa uma perspectiva normativa, na medida em que um planejamento estratégico é previamente definido, e a participação da comunidade é limitada ao papel de informante do potencial turístico das regiões, havendo pouco espaço para a tomada de uma posição atuante na definição de como deve ser conduzido o processo.

Nos anos 2000, é criado o Ministério do Turismo (com incorporação da Embratur), que passa a administrar exclusivamente a promoção do país e a orientar estudos de mercado e sua aplicação. A partir da criação do Ministério, é estabelecido um instrumento para aplicação da Política Nacional de Turismo, o Plano Nacional de Turismo. Desde a implantação do ministério, foram lançados até o momento três edições do Plano (2003-2007, 2007-2010 e 2013-2016), documentos que estabelecem as diretrizes para o desenvolvimento da atividade no país. Basicamente, os objetivos dos planos consistiam em:

- 2003-2007: Desenvolver o produto turístico brasileiro com base na diversidade regional, em seus aspectos culturais e naturais, estimular e facilitar o consumo do produto turístico brasileiro nos mercados nacional e internacional (BRASIL, 2003, p. 22).

- 2007-2010: Desenvolver o produto turístico com base na diversidade e aumentar sua competitividade; promover o turismo como fator de desenvolvimento social e aumentar a competitividade do produto (BRASIL, 2007, p. 16).

- 2013-2016: Preparar o turismo brasileiro para os megaeventos; incrementar a geração de divisas e a chegada de turistas estrangeiros; incentivar o brasileiro a viajar pelo Brasil, melhorar a qualidade e aumentar a competitividade do turismo brasileiro. 
Retomando brevemente o Plano 2003-2007, cabe destacar a proposta de promover o desenvolvimento regional com o Programa de Regionalização do Turismo, que consistiu em estabelecer um ordenamento da atividade com base no desenvolvimento de regiões turísticas agrupadas segundo afinidades. Considerando-se regionalização como "A organização do espaço geográfico em regiões para fins de planejamento, gestão, promoção e comercialização integrada e compartilhada da atividade turística" (BENI, 2006, p. 30), para a operacionalização do plano foram propostos mecanismos de governança regionais com vistas à descentralização da gestão.

Porém, a implementação dessas políticas não se consolidou. Embora o referencial para organização da atividade tenha se enriquecido e se estruturado, na prática, salvo exceções, houve fraca articulação entre municípios, regiões turísticas e destinos indutores. Municípios de pequeno e médio porte, sobretudo, continuaram a planejar a atividade turística de forma inadequada (ALMEIDA; COSTA, 2007, p. 2).

Beni (2006, p. 30) atribui os problemas à falta de capacitação das equipes municipais, opinião corroborada por Almeida e Costa (2007, p.7), que apontam como ponto negativo do programa a qualificação profissional deficiente dos recursos humanos, que acabou por afetar diretamente a qualidade da oferta turística, refletindo-se na avaliação apresentada no Plano 2003-2007. Nesse sentido, a análise actor-centered power pode ser uma ferramenta para identificar em nível micro (isto é, nas regiões e municípios) de que forma as relações de poder influenciam a implementação das políticas.

Esse cenário político é permeado por um plano conceitual, ou seja, por um debate acadêmico que fornece referências sobre as melhores condutas de planejamento. As diretrizes refletidas nas políticas públicas são influenciadas por aspectos teóricos, e, no Brasil, pode-se dizer que o modelo hegemônico está ancorado na teoria de sistemas. De acordo com Gets (apud LOHMANN; NETTO 2008, p. 27), existem 150 modelos de abordagens de turismo encontrados em publicações de língua inglesa e que se dividem em três grupos: (1) modelos teóricos; (2) processos de planejamento; (3) modelos de previsão. Presente nos três grupos, a teoria de sistemas, além de ser a mais aceita e discutida no meio acadêmico como um todo, caracterizando-se como o modelo teórico de referência, foi a abordagem que encontrou maior receptividade nas políticas públicas do Brasil.

Refletindo a teoria de sistemas, o Sistema de Turismo (Sistur) visa explicar as relações existentes entre o turismo, outras disciplinas e atividades humanas. 0 sistema, configurado como aberto, é composto por três conjuntos: (1) conjunto das relações ambientais e seus subsistemas - cultural, social, ambiental, econômico; (2) conjunto da organização estrutural e seus subsistemas - a superestrutura (pública e privada) e a infraestrutura (serviços urbanos, saneamento, sistema viário e de transportes, organização territorial, infraestrutura turística); (3) conjunto das relações operacionais, onde ocorre a dinâmica do turismo, composto pelos subsistemas de oferta, demanda, mercado, produção, distribuição, consumo.

O Plano Nacional de Turismo 2007-2010, cuja estrutura é obtida a partir de uma gestão descentralizada, organizada em Macro Programas, Câmaras Temáticas, Projetos e Ações, denota uma a tentativa de seguir uma orientação sistêmica. Mas, apesar da perspectiva teórica adotada, pode-se dizer que os objetivos econômicos (predominantes nas políticas de turismo brasileiras) acabaram prevalecendo. Para Molina (2001, p. 39), um dos desafios da gestão está no desenvolvimento conjunto de todos os subsistemas, uma vez que a aplicação das políticas 
públicas tende a priorizar uma das partes do sistema. Na primeira versão do Plano Nacional de Turismo, era elencada como objetivo a consideração de aspectos como qualidade, diversificação da oferta, estruturação dos destinos, qualificação da mão de obra e aumento da competitividade em nível nacional e internacional, além de aumento da taxa de permanência e gasto médio do turista.

Considerando o turismo como um sistema aberto em que ocorrem inter-relações entre conjuntos (Figura 1), podemos relacionar a teoria de sistemas aos três grandes grupos representados na organização do Plano Nacional de Turismo: (1) Gestão e Relações Institucionais, (2) Fomento à atividade e (3) Infraestrutura. Busca-se, assim, uma analogia entre os conjuntos que compreendem as diversificadas atividades turísticas em comparação aos campos de atuação do PNT.

Observando a Figura 1, pode-se identificar o sistema que busca estruturar a atividade turística. Entretanto, no conjunto das relações ambientais em contraponto às políticas expressa no PNT, constata-se que não há uma estrutura que busque harmonizar o conjunto, uma vez que os macroprogramas se dedicam ao conjunto das relações operacionais. Considerando ainda que, a partir do nível macro, os principais campos de ação demandam outras ações segmentadas, o sistema demonstra-se restrito. Ainda que em nível micro possam ser identificadas ações que englobem todo o sistema, deduz-se que esta organização favorece a centralização dos agentes mais poderosos em detrimento de propostas de base comunitária, por exemplo.

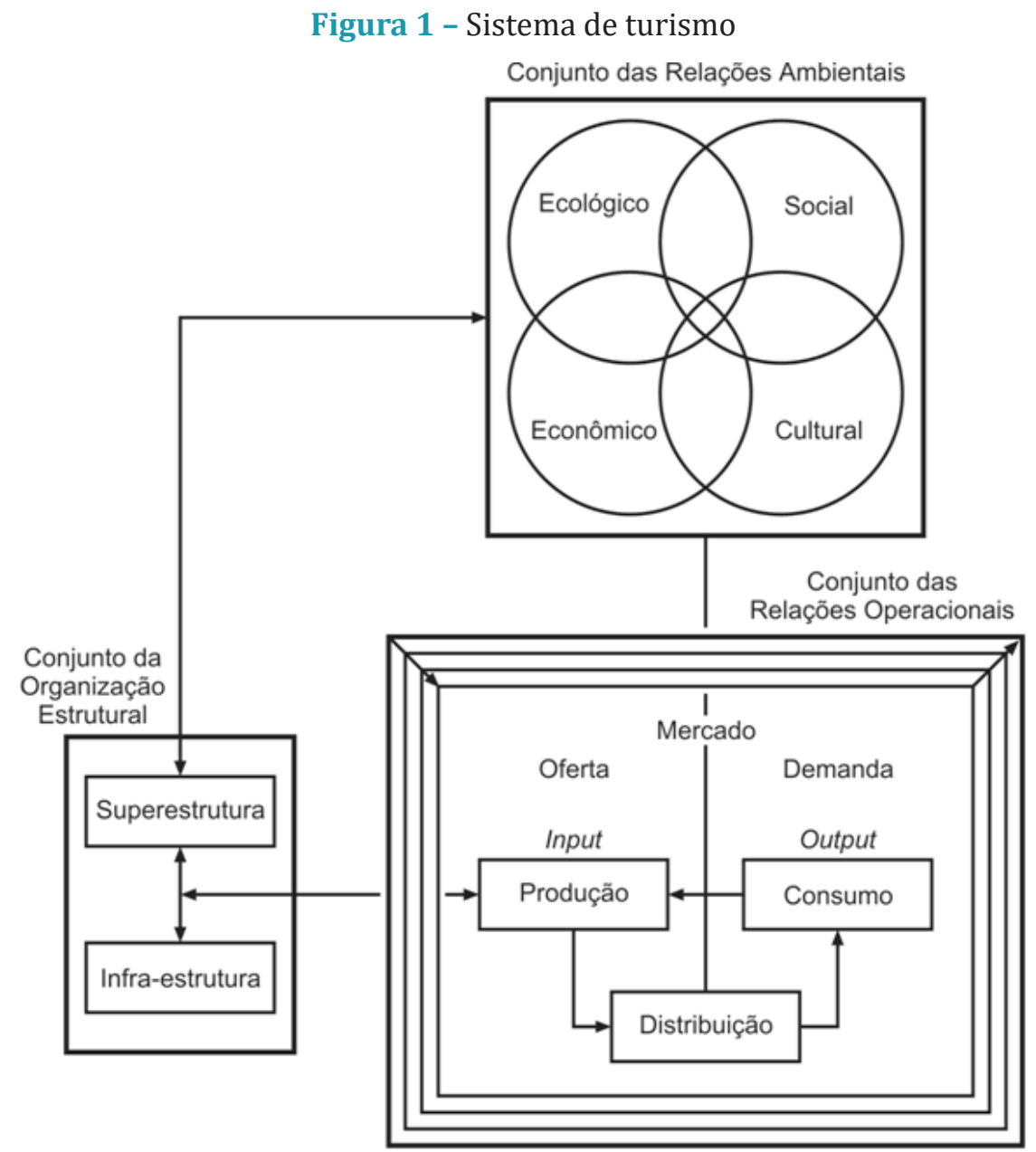

Fonte - Beni (1998, p. 48) 
O Plano Nacional de Turismo resultou na organização de um Plano de Regionalização da Oferta Turística do qual a Ilha Grande faz parte como integrante da região da Costa Verde, um destino associado ao turismo de sol e praia e vertentes de natureza. 0 plano propõe o agrupamento regional dos destinos segundo suas vocações, o que, por um lado, permite a criação de produtos turísticos, e, por outro, reforça uma perspectiva centrada nos agentes mais poderosos, como poderá ser verificado mais adiante.

O foco nas relações operacionais, conforme Bursztyn (2005, p. 91), caracteriza a recorrente visão de que um planejamento eficiente do turismo deve ter como meta alcançar os benefícios econômicos da atividade turística. Já no âmbito das políticas públicas, há o costumeiro discurso em que o turismo é tratado como um fim, e não como um meio de aprimorar as condições de vida dos residentes de localidades turísticas.

\section{ABORDAGEM DE PODER E ACTOR-CENTERED POWER: COERÇÃO, INCENTIVOS E DESINCENTIVOS, INFORMAÇÃO DOMINANTE}

Para efeitos deste estudo, toma-se o poder como a capacidade de um ator para mudar o comportamento de outro ator sem reconhecer a vontade deste último. 0 potentado é aquele que exerce força, enquanto o subordinado a recebe. Esse tipo de poder, de caráter político, é exercido na vida diária e a nível local. De acordo com Bramwell e Meyer (2007, p. 769),

o poder emerge das relações sociais, ao mesmo tempo sendo sustentado por padrões específicos de distribuição de recursos e da concorrência. As interações sociais que refletem relações de poder podem ser imbuídas de valores, significados, autoridade e controle.

Essas ações acontecem por meio de coerção ("alteração do comportamento de outro ator pela força"), incentivos e desincentivos ("alteração do comportamento de outro ator, fornecendo vantagens ou desvantagens") e informações dominantes ("alteração do comportamento de outro ator, devido às suas informações, que são aceitas sem verificação") (SCHUSSER et al., 2015, p. 6). Tais relações de poder podem ocorrer em vários níveis, desde os atores que se relacionam entre si com base em interesses comuns ou através de associações e ONGs, por exemplo. As relações conjuntas são maiores do que as individuais.

0 poder do ator e seus interesses podem direcionar o planejamento da atividade turística, fornecendo orientações para a concepção de turismo e de políticas públicas. A pesquisa é um meio de mostrar os interesses ocultos e o poder de atores importantes, uma vez que "a consciência das relações de poder ajuda a encontrar os atores certos que podem apoiar uma solução específica politicamente" (KROTT et al., 2014, p. 2). Portanto, de acordo com Krott et al. (2014, p. 2), actor-centered power é uma abordagem que:

- Especifica o processo de poder e seus elementos (ao descrever a sua constituição, pode-se entender que tipo de poder é estabelecido e como ele pode ser manipulado). 
- Aponta ligações de poder com atores específicos (identifica qual parte do poder está ligada a um determinado ator).

- Difere entre poder e outros recursos (nem todos os recursos são um sinal de poder).

- Observa incidentes empíricos que sugerem a presença de poder (a observação empírica é uma ferramenta para determinar a presença do poder).

Para efeitos deste estudo, o poder possui três características principais (coerção, incentivos e desincentivos, informação dominante) descritas a seguir.

\section{Coerção}

A coerção é o uso da força, ameaça de força ou de monitoramento, que pode levar a multas ou prisão. Uma área turística "exclusiva", onde a entrada de visitantes é proibida por meio de obstáculos (como cercas, por exemplo) e por força ou ameaça de força (com seguranças contratados para este fim), pode ser um exemplo de local onde vigoram formas de coerção.

Alguns tipos de coerção são amplamente observáveis no processo político, outras são secretas. Determinadas forças dentro de relações sociais são uma condição prévia para a presença do poder: a força técnica, por exemplo, correspondente ao conhecimento técnico, e a força financeira, decisiva em um contexto em que os mais ricos obterão vitórias. Aqueles atores que detêm conhecimento técnico ou condições financeiras são mais passíveis de usar de coerção contra indivíduos ou grupos. Não se deve confundir, porém, influência técnica com poder coercitivo. Para os distinguir, toma-se a força coercitiva como aquela que pode alterar o comportamento de um determinado agente independentemente de suas convicções. A coerção pode ser aplicada por um indivíduo ou uma rede de aliados formais e informais, sendo capaz de determinar um amplo campo de poder observável. Assim, os atores dotados de poder, responsáveis pela execução e acompanhamento da lei, podem prever sanções sobre outros (KROTT et al. 2014, p. 5).

\section{Incentivos e desincentivos}

Desincentivos são impostos independentemente da vontade dos atores afetados e alteram o comportamento do indivíduo. Por exemplo, os motivos para a proibição de construir em um determinado local são muitas vezes ignorados. Porém, conheçam-se ou não as justificativas para a norma, o fato é que o descumprimento da lei pode levar o indivíduo a ser multado. Sua própria vontade não conta nesse caso, e o indivíduo vê-se obrigado a aceitar a desvantagem devido ao risco de sanções.

Já os incentivos ocorrem quando o potentado oferece vantagens financeiras a fim de obter um comportamento específico por parte de determinado ator (KROTT et al. 2014, p. 5). A especulação imobiliária e a gentrificação, realidades 
no Brasil e na Ilha Grande, são exemplos de incentivos em que os detentores de recursos financeiros podem alterar o comportamento de atores menos favorecidos configurando determinadas relações de poder.

Os recursos, muito mais do que acordos, são a causa das mudanças de comportamento do subordinado. Há, no entanto, conflitos internos por parte dos atores afetados, que, por não terem sua vontade concretizada, não apoiarão as sanções de que são objeto (KROTT et al. 2014, p. 6).

\section{Informação dominante}

Um ator pode ser manipulado por outro através de informações não verificadas. Se o subordinado toma uma decisão ou altera seu comportamento com base em informações não verificadas fornecidas pelo potentado, estabelece-se uma relação de poder. Tal relação pode fazer com que o subordinado torne-se dependente do potentado, como no caso de discursos ideológicos, politicamente importantes, que geram uma relação de confiança entre os atores.

O processo voluntário de verificação de uma informação é menos importante do que a abstinência obrigatória. 0 subordinado geralmente é obrigado a aceitar esta informação devido à falta de informações relevantes direta ou falta de métodos ou recursos. 0 conhecimento especializado é um exemplo, pois a maioria da comunidade é composta de pessoas sem educação formal. Especialistas têm as informações e são capazes de verificá-la, enquanto os outros só podem acreditar neles. (KROTT et al. 2014, p. 6)

Esse tipo de dominação, no entanto, nem sempre se estabelece. No processo de poder, a informação dominante pode, por vezes, ser usada em favor dos interesses do subordinado. As comunidades locais, por exemplo, podem obter aconselhamento especializado capaz de ajudá-las. Mas, caso o comportamento dessas comunidades seja altamente influenciado pela vontade do perito, pode estabelecer-se novamente um processo de poder. A comunidade local estará exposta ao poder do potentado sempre que se esquecer ou deliberadamente não querer verificar as informações que lhe são fornecidas (DEVKOTA, 2010 apud KROTT et al. 2014, p. 7).

A abordagem actor-centered power está ligada diretamente aos atores que agem como subordinados ou potentados, a depender de suas fontes de poder. Os atores mais poderosos podem ser identificados pelo acúmulo de funções como potentado. 0 modelo não pressupõe, entretanto, que os atores mais poderosos o sejam sempre, já que, em situações específicas, é possível que atuem como subordinados. Essa hipótese se comprova por observações nas quais um ator específico pode dominar por algum tempo, mas não sempre nem em todas as situações (SCHUSSER et al., 2015, p. 3). O papel de potentado pode ser, portanto, uma condição temporária.

As relações de poder somente serão consideradas como tais quando o comportamento de um ator for modificado por outro através de coerção, incentivos ou desincentivos e informação dominante. 


\section{MÉTODOS}

A Ilha Grande faz parte do município de Angra dos Reis (RJ), localizado na região conhecida como Costa Verde (Figura 2), uma das áreas mais visitadas do Rio de Janeiro.

Figura 2 - Localização da Ilha Grande segundo Regiões Turísticas do Rio de Janeiro

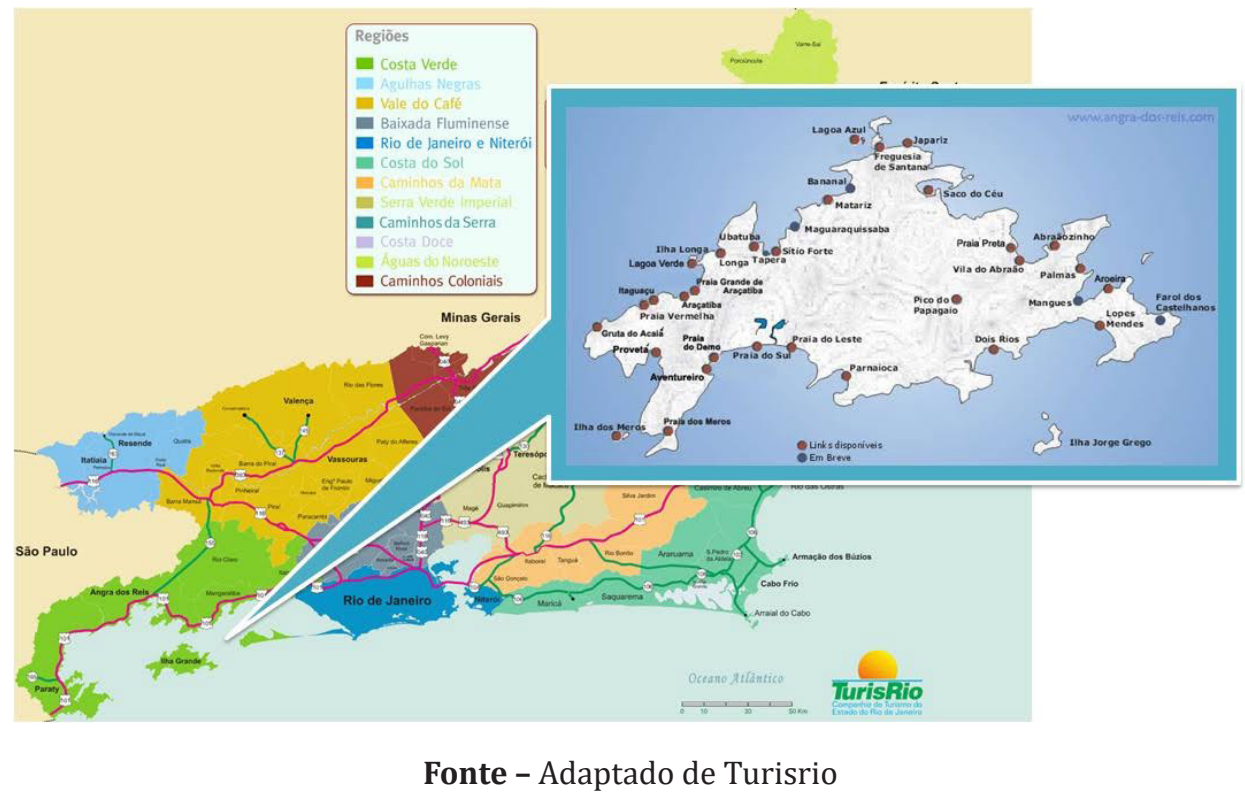

O Parque Estadual da Ilha Grande (PEIG), objeto de estudo desta pesquisa, foi criado através do Decreto ${ }^{\circ} 15.273$ de 28 de junho de 1971, demarcado pelo Decreto ${ }^{\circ} 16.067$ de 4 de junho de 1973 e disposto pelo Decreto ${ }^{\circ} 2.061$ de 25 de agosto de 1978, ocupando 5.594 dos 19.300 hectares da área total da ilha. Suas 34 pontas, sete enseadas e 106 praias são seus maiores atrativos naturais, visitados principalmente durante o verão. 0 Pico da Pedra d'Água e o Pico do Papagaio são os de maior altitude, com 1.031 e 982 metros, respectivamente. Seu clima é tropical, quente e úmido, sem estação seca. A temperatura do ar varia entre $15^{\circ} \mathrm{C}$ e $30^{\circ} \mathrm{C}$, sendo a média anual de $22,5^{\circ} \mathrm{C}$. A temperatura média da água do mar varia de $18^{\circ} \mathrm{C}$ a $24^{\circ} \mathrm{C}$. Os dias de sol variam de 180 a 200 por ano (PROGRAMA NACIONAL DO MEIO AMBIENTE, 1997; UFRRJ, 1993).

Em 2007, o PEIG foi ampliado em 6.458 hectares, passando a ocupar 12.072 hectares do território da Ilha Grande. Sua administração, anteriormente subordinada ao Instituto Estadual de Florestas (IEF), passou a ser de responsabilidade do Instituto Estadual do Ambiente (Inea), órgão vinculado à Secretaria de Estado do Ambiente (SEA). Segundo maior parque insular brasileiro, o PEIG é considerado Reserva da Biosfera da Mata Atlântica pela UNESCO desde 1992 e tombado como patrimônio do estado do Rio de Janeiro desde 1987 (INEA, 2013, p. 13-18).

0 turismo em massa teve início na Ilha Grande após a desativação do Instituto Penal Cândido Mendes em 1994. Na verdade, sempre houve atividade turística na ilha, mas a existência da prisão mantinha a maioria dos turistas a distância. Depois de 1994, o turismo cresceu rapidamente e de forma espontânea, apresentando um novo cenário aos habitantes da ilha. Com o local convertido em destino 
turístico, muitas partes interessadas começaram a investir em construção, iniciando uma grande transformação na paisagem e na vida social dos moradores.

A partir do crescimento da atividade turística, muitos atores com interesses conflitantes começaram a surgir: ONGs dedicadas à conservação da natureza foram criadas, áreas protegidas estabelecidas, e, enquanto empresários necessitavam de mais clientes, residentes desejavam uma vida tranquila ou trabalhar com turismo.

Para a realização deste estudo, entrevistas com nove atores sociais considerados mais poderosos foram levadas a cabo em novembro de 2014. Os atores foram selecionados através do processo de bola de neve, iniciado com um representante do Instituto Estadual do Ambiente, a maior entidade relacionada ao PEIG, administradora da Unidade de Conservação. A partir das indicações do representante, outros atores eram selecionados para entrevista.

Segundo Vinuto (2014, p. 201), a amostragem não probabilística bola de neve utiliza cadeias de referência a fim de acessar grupos de atores em um universo não quantificável. Assim, ao iniciar a amostragem com o representante da instituição administradora do PEIG, foi possível identificar uma cadeia de referências em que um ator menciona outros com interesses comuns ou que ofereçam apoio àquela instituição, gerando uma rede de colaboradores. É normalmente utilizada em pesquisa de teor sociológico, especialmente quando se busca o conhecimento de atividades privadas ou internas, que demandam a contribuição de atores locais para que os entrevistados sejam localizados e identificados (BIERNACKI; WALDORF, 1981, p. 141).

As entrevistas foram gravadas com autorização dos entrevistados e tiveram duração média de cinquenta minutos. 0 objetivo era entender as relações de poder entre os entrevistados e seus interesses no que tange ao desenvolvimento do turismo no parque. 0 processo bola de neve permitiu identificar atores poderosos, que se apoiam mutuamente durante as entrevistas. As instituições citadas foram:

- Liga Cultural Afro-Brasileira: associação de cunho cultural que visa o incentivo à capoeira, à ciranda, ao cinema e a construção de uma biblioteca.

- Associação dos Meios de Hospedagem da Ilha Grande (AMHIG): associação/representante de outros grupos composta por vinte pousadeiros na Vila do Abraão. Busca capacitar profissionalmente os pousadeiros e visa a preservação ambiental, pois acredita que a natureza é o principal atrativo da Ilha Grande.

- Brigada Mirim Ecológica: associação que oferece atividades diversificadas (agricultura, maricultura e educação ambiental) a jovens de catorze a dezessete anos. Os participantes distribuem aos turistas panfletos sobre educação ambiental e sacos de lixo.

- Comitê de Defesa da Ilha Grande (Codig): ONG voltada a questões ambientais, sociais e turísticas. 
- Associação Curupira de Guias e Condutores de Visitantes da Ilha Grande: associação que engloba guias credenciados pela Embratur e condutores informais.

- Instituto Estadual do Ambiente (Inea): administração pública/turística que administra o PEIG.

- Organização para a Sustentabilidade da Ilha Grande (Osig): ONG de cunho ambiental voltada para questões de sustentabilidade local.

- Jornal O Eco: mídia dedicada a abordar questões pertinentes ao desenvolvimento da Ilha Grande.

- Fundação de Turismo de Angra dos Reis (TurisAngra): órgão público de administração que visa gerir o turismo através da elaboração de políticas e divulgação do destino.

O seguinte quadro foi elaborado no intuito de classificar teoricamente os tipos de atores que podem exercer poder sobre uma localidade turística.

Quadro 1 - Classificação teórica dos atores sociais, definições e exemplos

\begin{tabular}{|c|c|c|}
\hline Ator & Definição & Exemplo \\
\hline \multicolumn{3}{|l|}{ Político } \\
\hline Político & $\begin{array}{l}\text { Ator que é eleito pelo povo para } \\
\text { exercer mandato público e pode } \\
\text { legitimar decisões. }\end{array}$ & $\begin{array}{l}\text { Governo e ministros, } \\
\text { representações de partidos } \\
\text { políticos, congresso etc. }\end{array}$ \\
\hline Administração pública & $\begin{array}{l}\text { Ator público que toma decisões } \\
\text { sobre problemas específicos } \\
\text { com base em normas legais } \\
\text { gerais, resolvendo problemas } \\
\text { e implementando medidas } \\
\text { específicas (KROTT, 2005). }\end{array}$ & $\begin{array}{l}\text { Autoridade de conservação da } \\
\text { natureza, autoridade de uso da } \\
\text { terra, autoridade de agricultura, } \\
\text { polícia, militares etc. }\end{array}$ \\
\hline Administração turística & $\begin{array}{l}\text { Administração pública com foco } \\
\text { na gestão da visitação. }\end{array}$ & $\begin{array}{l}\text { Departamento de turismo, } \\
\text { escritório de turismo, diretório de } \\
\text { turismo. }\end{array}$ \\
\hline Líder tradicional & $\begin{array}{l}\text { Ator legitimado para exercer } \\
\text { mandato público e que pode } \\
\text { legitimar decisões em uma } \\
\text { comunidade. }\end{array}$ & $\begin{array}{l}\text { Líderes de vilarejos, curandeiros, } \\
\text { autoridade tradicional, líder } \\
\text { religioso etc. }\end{array}$ \\
\hline Conselho & $\begin{array}{l}\text { Ator constituído por políticos, } \\
\text { líderes tradicionais ou } \\
\text { administrativos com mandato } \\
\text { público. }\end{array}$ & $\begin{array}{l}\text { Conselho de turismo, conselho de } \\
\text { uso da terra, conselho de controle } \\
\text { público, conselho de meio } \\
\text { ambiente etc. }\end{array}$ \\
\hline Organização doadora & $\begin{array}{l}\text { Ator que oferece recursos } \\
\text { financeiros para a resolução de } \\
\text { problemas. }\end{array}$ & $\begin{array}{l}\text { Bancos nacionais e internacionais } \\
\text { e outras organizações. }\end{array}$ \\
\hline
\end{tabular}

(continua...) 


\section{Quadro 1 - Continuação}

\begin{tabular}{|c|c|c|}
\hline Ator & Definição & Exemplo \\
\hline Associação & $\begin{array}{l}\text { Ator que articula os interesses } \\
\text { do grupo que representa e tenta } \\
\text { implementá-los através de lobby } \\
\text { com políticos e administração } \\
\text { pública (KROTT, 2005). }\end{array}$ & $\begin{array}{l}\text { Associação de turismo, associação } \\
\text { de hotéis, associação de } \\
\text { moradores, associação de meio } \\
\text { ambiente etc. }\end{array}$ \\
\hline Associação de apoio & $\begin{array}{l}\text { Ator que pode ser caracterizado } \\
\text { como associação, mas também } \\
\text { oferece fundos para solução de } \\
\text { problemas. }\end{array}$ & ONGs e OSCIPs. \\
\hline \multicolumn{3}{|l|}{ Econômico } \\
\hline $\begin{array}{l}\text { Representante de } \\
\text { grupos de comunidades } \\
\text { locais }\end{array}$ & $\begin{array}{l}\text { Ator que articula os interesses } \\
\text { dos grupos de comunidades } \\
\text { locais e tenta implementá-los. }\end{array}$ & $\begin{array}{l}\text { Comitês de gestão de } \\
\text { comunidades locais, comitê } \\
\text { de desenvolvimento, comitê } \\
\text { de conservação da natureza, } \\
\text { conselho gestor etc. }\end{array}$ \\
\hline $\begin{array}{l}\text { Representante de } \\
\text { outros grupos }\end{array}$ & $\begin{array}{l}\text { Ator que articula os interesses } \\
\text { de outros grupos de } \\
\text { comunidades locais e tenta } \\
\text { implementá-los. }\end{array}$ & \\
\hline $\begin{array}{l}\text { Empreendedor } \\
\text { turístico }\end{array}$ & $\begin{array}{l}\text { Ator que usa o turismo para } \\
\text { maximização de lucros. }\end{array}$ & $\begin{array}{l}\text { Hotéis, restaurantes, operadores, } \\
\text { agências de turismo, escolas de } \\
\text { mergulho, navios de cruzeiro, } \\
\text { aluguel de barcos, planejamento } \\
\text { de eventos e outros serviços } \\
\text { relacionados. }\end{array}$ \\
\hline Consultoria & $\begin{array}{l}\text { Ator que fornece informação, } \\
\text { fundos e gestão para outro ator. }\end{array}$ & Consultorias. \\
\hline \multicolumn{3}{|l|}{ Social } \\
\hline Instituição de pesquisa & $\begin{array}{l}\text { Ator que fornece conhecimento } \\
\text { baseado na ciência. }\end{array}$ & $\begin{array}{l}\text { Universidades, centros de } \\
\text { pesquisa etc. }\end{array}$ \\
\hline Mídia & $\begin{array}{l}\text { Atores que distribuem e geram } \\
\text { informação. }\end{array}$ & $\begin{array}{l}\text { Mídia nacional e internacional, } \\
\text { como jornais, revistas, estações } \\
\text { de rádio, canais de TV etc. }\end{array}$ \\
\hline Organização religiosa & $\begin{array}{l}\text { Ator que fornece auxílio } \\
\text { espiritual ou religioso. }\end{array}$ & $\begin{array}{l}\text { Igrejas, mesquitas, associações } \\
\text { religiosas ou espirituais etc. }\end{array}$ \\
\hline Visitante & $\begin{array}{l}\text { Ator que influencia os aspectos } \\
\text { econômicos e sociais de uma } \\
\text { comunidade em busca de lazer. }\end{array}$ & $\begin{array}{l}\text { Turistas e proprietários de } \\
\text { segundas residências. }\end{array}$ \\
\hline
\end{tabular}

Fonte - Adaptado de Schusser et al. (2015)

\section{RESULTADOS}

A partir da observação de campo, pôde-se identificar alguns atores do PEIG. A seguir, apresenta-se a distribuição desses atores em categorias. 
Quadro 2 - Atores políticos, econômicos e sociais no Parque Estadual da Ilha Grande

\begin{tabular}{|c|c|}
\hline Ator & Ator no Parque Estadual da Ilha Grande \\
\hline \multicolumn{2}{|l|}{ Político } \\
\hline Político & Presidente, governador, prefeito, subprefeito etc. \\
\hline Administração pública & $\begin{array}{l}\text { Inea*, governos federal, estadual e municipal, } \\
\text { Subprefeitura, Ministério Público, Secretaria de } \\
\text { Turismo etc. }\end{array}$ \\
\hline Administração turística & $\begin{array}{l}\text { Inea*, TurisAngra*, Ilha Grande Convention and } \\
\text { Visitors Bureau etc. }\end{array}$ \\
\hline Líder tradicional & Caiçaras. \\
\hline Conselho & $\begin{array}{l}\text { Conselho Consultivo do Parque Estadual da Ilha } \\
\text { Grande, Conselho Consultivo da Área de Proteção } \\
\text { Ambiental de Tamoios, Conselho Consultivo do } \\
\text { Mosaico da Bocaina etc. }\end{array}$ \\
\hline Organização doadora & $\begin{array}{l}\text { Vale, Termorio, KfW, Tetra Pak, Klabin, } \\
\text { Eletronuclear etc. }\end{array}$ \\
\hline Associação & $\begin{array}{l}\text { Brigada Mirim Ecológica*, AMAIG, AMHIG*, } \\
\text { Curupira*, Apeb, IACV, Isabi, Amav, Amotap, } \\
\text { AMVDR, AAPAA, Liga Cultural Afro-Brasileira* etc. }\end{array}$ \\
\hline Associação de apoio & $\begin{array}{l}\text { Cio da Terra, Codig*, Sape, Parceiros da Terra, } \\
\text { Osig*, Consig etc. }\end{array}$ \\
\hline \multicolumn{2}{|l|}{ Econômico } \\
\hline $\begin{array}{l}\text { Representante de grupos de } \\
\text { comunidades locais }\end{array}$ & AMAIG, Associação de Pescadores, Piajig, OPA etc. \\
\hline Representante de outros grupos & ABIG, AMHIG* etc. \\
\hline Empreendedores turísticos & $\begin{array}{l}\text { Hotéis, restaurantes, operadores e agências de } \\
\text { turismo etc. }\end{array}$ \\
\hline Consultor & $\begin{array}{l}\text { Agência 21, Sebrae, Instituto BioAtlântica, Instituto } \\
\text { Ondular, Consultoria Ambiental etc. }\end{array}$ \\
\hline \multicolumn{2}{|l|}{ Social } \\
\hline Instituição de pesquisa & Uerj, Ceads etc. \\
\hline Mídia & O Eco* etc. \\
\hline Organizaçãoreligiosa & Igrejas católicas e protestantes etc. \\
\hline Visitantes & Turistas e proprietários de segunda residência. \\
\hline
\end{tabular}

*Atores entrevistados

Para efeito deste estudo, foram elencados os atores e seu nível de apoio (observado empiricamente) ao planejamento do turismo. Os atores foram classificados em três níveis de apoio:

- Alto: apoia totalmente o planejamento do turismo na Ilha Grande.

- Médio: apoia parcialmente o planejamento do turismo na Ilha Grande.

- Baixo: não apoia o planejamento do turismo na Ilha Grande. 
Para a análise actor-centered power, foram definidos os seguintes critérios para cada elemento do poder, relacionados aos interesses de cada ator no desenvolvimento do turismo na Ilha Grande:

- Coerção (direitos legais): alto, médio, baixo ou inexistente.

- Incentivos e desincentivos (meios financeiros): alto, médio, baixo ou inexistente.

- Informação dominante (expertise e conhecimento): alto, médio, baixo ou inexistente.

O Quadro 3 reúne os resultados de acordo com as entrevistas realizadas.

Quadro 3 - Elementos de poder e apoio ao planejamento do turismo por parte dosentrevistados

\begin{tabular}{|l|c|c|c|c|}
\hline Ator & $\begin{array}{c}\text { Apoio ao } \\
\text { planejamento do } \\
\text { turismo }\end{array}$ & Coerção & $\begin{array}{c}\text { Incentivos e } \\
\text { desincentivos }\end{array}$ & $\begin{array}{c}\text { Informação } \\
\text { dominante }\end{array}$ \\
\hline $\begin{array}{l}\text { Liga Cultural } \\
\text { Afro-Brasileira }\end{array}$ & Alto & Inexistente & Baixo & Baixo \\
\hline AMHIG & Alto & Médio & Baixo & Baixo \\
\hline $\begin{array}{l}\text { Brigada Mirim } \\
\text { Ecológica }\end{array}$ & Alto & Médio & Médio & Médio \\
\hline Codig & Alto & Médio & Baixo & Alto \\
\hline $\begin{array}{l}\text { Associação } \\
\text { Curupira }\end{array}$ & Alto & Baixo & Baixo & Médio \\
\hline Inea & Alto & Alto & Alto & Alto \\
\hline Osig & Alto & Médio & Médio & Alto \\
\hline O Eco & Alto & Médio & Baixo & Alto \\
\hline TurisAngra & Alto & Alto & Alto & Alto \\
\hline
\end{tabular}

Como se pode observar, todos os atores entrevistados apoiam o planejamento do turismo, especialmente a implementação do estudo de capacidade de carga, citado por todos como fundamental para o ordenamento do turismo na Ilha Grande, cujo número de visitantes excede o desejado pelos entrevistados.

\section{Análise actor-centered power}

Ao descrever a constituição do poder e de seus elementos, a análise actor-centered power compreende e especifica os tipos de poder estabelecidos e aponta para como estes podem ser manipulados.

Por meio das entrevistas, pôde-se observar que os atores mais poderosos na atividade turística de Ilha Grande são o Inea e a TurisAngra, instituições que reúnem condições de influenciar outros atores através de coerção, incentivos ou desincentivos e informação dominante. Por ser administrador do PEIG, o Inea obtém vantagens com seu posicionamento, podendo direcionar políticas públicas para o local. A TurisAngra, por sua vez, detém o poder de interferir nas atividades de turismo 
da Ilha Grande por ser o órgão público responsável por sua administração. A maior expressão de poder do Inea e da TurisAngra é a informação dominante, pois ambos atores detêm conhecimento técnico que pode não ser verificado por outros atores, especialmente a comunidade local, que confia nessas informações. A coerção pode ser utilizada pelo Inea na forma da delimitação de regras de uso e comportamento no PEIG e pode ser verificada no monitoramento e nos incentivos e desincentivos em forma de multas para aqueles que não cumprem as normas estabelecidas.

\section{Ligações de poder para atores específicos}

Traçando as ligações de poder para atores específicos, pode-se identificar qual parte do poder (coerção, incentivos e desincentivos e informação dominante) está ligada a um determinado ator. 0 Quadro 3 identifica os elementos de poder e os liga a seus respectivos atores, indicando as instituições governamentais como mais poderosas, seguidas pelas organizações não-governamentais. Os menos poderosos são as associações e a mídia local. No entanto, as relações de poder são mutáveis ao longo do tempo, ou seja, os atores alternam seu impacto de poder de acordo com a situação política ou econômica em nível local ou nacional.

\section{Diferenças entre poder e outras características}

Cabe observar que nem todos os recursos são um sinal de poder. As ONGs entrevistadas (Codig, Osig e Brigada Mirim Ecológica) e o Jornal O Eco não são consideradas poderosas de acordo com a análise individual de seus elementos, porém exercem enorme pressão sobre o poder público no que tange ao direcionamento de políticas públicas para a Ilha Grande, possuindo grande informação dominante. Por outro lado, a atuação da TurisAngra, considerada poderosa, foi caracterizada como "pífia" por um dos entrevistados, já que sua interferência nos processos de planejamento é mínima, considerando sua alta carga de poder. Entretanto, no que pese a efetividade de tal comentário, TurisAngra e Inea seguem sendo aquelas instituições que realmente têm o poder de alterar o comportamento de outros atores através dos elementos citados. O PEIG possui conselho consultivo e, apesar de todos os atores entrevistados fazerem parte e participarem ativamente do órgão, a decisão final sempre cabe ao Inea, o que faz com que as demandas da comunidade local nem sempre sejam atendidas.

\section{Observação de incidentes empíricos}

Observações empíricas são uma ferramenta para determinar a presença do poder. As entrevistas são direcionadas aos atores de forma a identificar os meios que cada um possui para cada elemento de poder. A análise de estatutos e contratos de serviços também podem ser usados nessa identificação. As entrevistas visam identificar quais atores se apoiam mutuamente e quais são mais influentes no atual cenário turístico local, além de seus interesses, muitas vezes escondidos, mas que podem ser verificados empiricamente. No Quadro 3, estão elencados os 
atores mais poderosos, formando uma rede de apoio que perpetua esse poder frente a outros atores. Inea e TurisAngra são os mais poderosos e teoricamente seriam grandes parceiros, porém as entrevistas identificaram que o Inea normalmente obtém mais apoio das ONGs relacionadas, pois seus interesses em relação ao desenvolvimento do turismo são mais próximos.

O cenário analisado no PEIG pode ser comparado ao caso da Indonésia, onde o conflito de interesses dos atores envolvidos ocasiona entraves na gestão de áreas protegidas. A fim de mitigar esses conflitos, duas políticas públicas que visam encorajar a participação comunitária foram desenvolvidas: devolução (sistema de gestão que prioriza o conhecimento local para conservar a biodiversidade) e descentralização (flexibilização do poder do governo central para regiões) (EVANS et al. apud KUSTANTI et al., 2014, p. 154).

No Canadá, Reed (1997, p. 579) aponta que a grande barreira para o desenvolvimento do turismo foi a falta de apoio de altas instâncias do governo para liberar terrenos para iniciativas específicas, além da frustação com relação à falta de cooperação para identificar necessidades locais, especificamente na província de Squamish. 0 conflito de interesses no desenvolvimento do turismo também é abordado como sendo um dos entraves ao planejamento. Enquanto alguns atores desejam manter as características originais do local, outros defendem que grandes equipamentos turísticos sejam instalados.

Em Lombok, uma pequena ilha na Indonésia, os autores alertam para os custos sociais do turismo como ferramenta de desenvolvimento em países emergentes através da análise de tipos de poder e seus efeitos em diferentes atores. Os efeitos negativos do turismo em pequenas ilhas podem ser extremos dependendo das características socioculturais da população local, que pode sofrer com a estrutura de poder exercido sobre seu território (HAMPTON; JEYACHEYA, 2015, p. 481).

É importante observar que os problemas relativos aos entraves ao planejamento do turismo na Ilha Grande são semelhantes aos casos supracitados e, possivelmente, a outros no Brasil e em países em desenvolvimento. 0 caso do PEIG, portanto, pode ser referencial para estudos congêneres em outras ilhas e áreas protegidas, onde as relações de poder podem ser analisadas segundo a metodologia apresentada.

\section{CONCLUSÃo}

As teorias normativas de planejamento turístico no Brasil permitem uma visão clara dos passos a se seguir para a implementação do turismo em locais diversos. Entretanto, os interesses dos atores poderosos podem direcionar esse processo mais que o próprio plano. Nesse cenário, a detecção dos atores e seus elementos de poder (coerção, incentivos e desincentivos e informação dominante) é uma ferramenta útil para a identificação dos interesses envolvidos.

A perspectiva normativa do planejamento turístico, centrada nas relações de mercado, é eficaz em seus princípios teóricos, pois oferece uma visão integrada criada a partir de estruturas de organização do conhecimento da atividade. Essa perspectiva teve um importante papel ao organizar um todo complexo composto por diferentes setores da economia. Entretanto, como afirmado anteriormente, o 
planejamento do turismo no PEIG não vem alcançando os resultados esperados devido aos interesses conflitantes dos diversos atores envolvidos no processo.

A Ilha Grande possui atores interessados em diversos cenários de desenvolvimento, que, por vezes, podem ser conflitantes, dificultando o processo de planejamento. Faz-se necessária uma pesquisa mais aprofundada a respeito desses interesses, principalmente levando-se em conta que a Ilha Grande, para além do PEIG, é um mosaico de vilarejos, cada um com seus aspectos culturais e sociais distintos. Portanto, o planejamento do turismo e a resolução de conflitos requerem uma análise profunda dos atores envolvidos e de seus interesses de desenvolvimento, para que assim se possa alcançar, na prática, o sucesso.

\section{REFERÊNCIAS}

ALMEIDA, É.; COSTA, C. O planejamento turístico entre os municípios brasileiros de pequena e média dimensão. Revista Acadêmica do Observatório de Inovação do Turismo, Rio de Janeiro, v. 2, n. 1, p. 1-20, 2007.

BENI, M. C. Política e planejamento do turismo no Brasil. São Paulo: Aleph, 2006.

BEZERRA, D. M. F. (Org.). Planejamento e gestão em turismo. São Paulo: Roca, 2003.

BIERNACKI, P.; WALDORF, D. Snowball sampling: problems and techniques of chain referral sampling. Sociological methods and research, [s. l.], v. 10, n. 2, p. 141-163, 1981.

BRAGA, D. C. Planejamento turístico: teoria e prática. Rio de Janeiro: Campus, 2006.

BRAMWELL, B., MEYER, D. Power and tourism policy relations in transition. Annals of Tourism Research, Amsterdam, v. 34, n. 3, p. 766-788, 2007.

BRASIL. Ministério do Turismo. Plano Nacional de Turismo: 2007-2010. Brasília: Ministério do Turismo, 2007. Disponível em: <http://bit.ly/2nfyGkF>. Acesso em: 4 abr. 2016.

BRASIL. Ministério do Turismo. Plano Nacional do Turismo: diretrizes, metas e programas: 2003-2007. Brasília: Ministério do Turismo, 2003. Disponível em: <http://bit. ly/2nXr9Ed>. Acesso em: 4 abr. 2016.

BURSZTYN, I. Políticas Públicas de Turismo visando a Inclusão Social. 2005. Dissertação (Mestrado em Ciências em Engenharia de Produção) - Universidade Federal do Rio de Janeiro, Rio de Janeiro, 2005.

HAMPTON, M. P.; JEYACHEYA, J. Power, ownership and tourism in small islands: evidence from Indonesia. World Development, London, v. 70, p. 481-495, 2015.

INEA - INSTITUTO ESTADUAL DO AMBIENTE. Parque Estadual da Ilha Grande (PEIG): Plano de manejo (fase 2). Rio de Janeiro: Inea, 2013. Disponível em: <http://bit.ly/2n7lAFO >. Acesso em: 20 mar. 2017.

KROTT, M. Forest policy analysis. Dordrecht: Springer, 2005.

KROTT, M. et al. Actor-centered power: the driving force in decentralized community based forest governance. Forest Policy and Economics, Amsterdam, v. 49, p. 34-42, 2014.

KUSTANTI, A. et al. Actor, interest and conflict in sustainable mangrove forest management: a case from Indonesia. International Journal of Marine Science, British Columbia, v. 4, n. 16, p. 150-159, 2014.

LOHMANN, G.; NETTO, A. Teoria do turismo: conceitos, modelos e sistemas. São Paulo: Aleph, 2008. 
MARYUDI, A. et al. Back to basics: considerations in evaluating the outcomes of community forestry. Forest Policy and Economics, Amsterdam, v. 14, n. 1, p. 1-5, 2012.

MOLINA, S. Planejamento integral do turismo: um enfoque para a América Latina. Bauru: Edusc, 2001.

PANOSSO NETO, A.; ANSARAH, M. G. R. (Org.). Segmentação do mercado turístico: estudos, produtos e perspectivas. São Paulo: Manole, 2008.

PETROCCHI, M. Turismo: planejamento e gestão. São Paulo: Futura, 1998.

PROGRAMA NACIONAL DO MEIO AMBIENTE. Programa de gestão para o desenvolvimento sustentável da bacia contribuinte à baía da Ilha Grande: volume 1: diagnóstico ambiental da baía da Ilha Grande. Brasília: SEMA, 1997.

REED, M. G. Power relations and community-based tourism planning. Annals of Tourism Research, Amsterdam, v. 24, n. 3, p. 566-591, 1997.

RUSCHMANN, D.; SOLHA, K. T. Planejamento turístico. Barueri: Manole, 2005.

SCHUSSER, C. Who determines biodiversity? An analysis of actor's power and interests in community forestry in Namibia. Forest Policy and Economics, Amsterdam, v. 36, p. 42$51,2013$.

SCHUSSER, C. et al. Comparing community forestry actors in Cameroon, Indonesia, Namibia, Nepal and Germany. Forest Policy and Economics, Amsterdam, v. 68, p. 81-87, 2016.

SCHUSSER, C. et al. Powerful stakeholders as drivers of community forestry: results of an international study. Forest Policy and Economics, Amsterdam, v. 58, p. 92-101, 2015.

SOLHA, K. T. Evolução do Turismo no Brasil. In: REJOWSKI, M. (Org.) Turismo no percurso do tempo. São Paulo: Aleph, 2002. p. 117-152.

UFRRJ - UNIVERSIDADE FEDERAL RURAL DO RIO DE JANEIRO. Plano diretor do Parque Estadual da Ilha Grande. Rio de Janeiro: UFRRJ, 1993.

VINUTO, J. A amostragem em bola de neve na pesquisa qualitativa: um debate em aberto. Temáticas, Campinas, v. 44, p. 203-220, 2014.

Recebido em: 10/05/2016 Aprovado em: 16/03/2017 